\title{
The Effect Of LTO Culture On International Supply Chain Contracts
}

Sungmin Ryu, (E-mail: sryu@suffolk .edu), Suffolk University

Martha Cook, (E-Mail: Martha_Cook@Baruch.cuny.edu), Baruch College/City University of New York

\begin{abstract}
Effective management of international supply chain relationships is critical in determining the success of the ever-growing cadré of international businesses where small cost differentials separate profitable enterprises from failed ones. Because inter-organizational contractual arrangements define expectations and standards for supply chain transactions, they may play a role in determining relationship efficiencies (and thus costs.) Although the effect of culture on the functioning of interfirm relationships in the supply chain has been an active area of scholarly investigation in the past decade, most studies have focused on organizations in Western societies, particularly in the US and Europe. Increasingly, global supply chains include at least one Asian partner so that cultural patterns predominant in the East must also be considered. This study examines the cultural factor of time orientation and seeks to understand how the long-term orientation (LTO) characterizing many Eastern cultures may affect supply chain contracts. Specifically, it investigates the influence of cultural time-orientation on the formation of soft (implicit, general) and hard (written, detailed) contracts. The results underscore the importance of culture in managing effective interfirm relationships in the supply chain: Long-term orientation culture tends to rely upon and function successfully with soft contracts, but does not depends on hard contracts.
\end{abstract}

\section{INTRODUCTION}

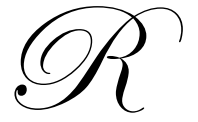

ecent scholarly attention to governance mechanisms in the area of organizational relationships in the supply chain has improved understanding of the contractual relationship between exchange parties. Scholars have identified important factors influencing contractual relationships: environmental uncertainty (Cannon, Achrol, and Gundlach 2000), relationalism (Antia and Frazier 2001), purchasing volume (Buvik and Reve 2001), transaction specific investment (Antia and Frazier 2001; Buvik and Reve 2001; Cannon, Achrol, and Gundlach 2000), interdependence magnitude (Antia and Frazier 2001, Lusch and Brown 1996), and interdependence asymmetry (Antia and Frazier 2001; Etgar and Vanency 1983). All of these have demonstrated effects on the nature of contractual relationships and on the measure of success they enjoy.

There is a gap in this body of research: The influence of culture, a macro factor, has not been examined with the same thoroughness. Comparative research analyzing the influence of culture on exchange parties' behavior in different cultures has been rare (Chang \& Ding 1995). This limits the confidence with which one might generalize relationship characteristics when exchange parties from dissimilar cultures are studied (Doney \& Cannon 1997). As the global economy expands, exchange partners from the East and the West interact with increasing frequency. Surely, East-Asian countries such as Korea, Japan, China, Taiwan, and Hong Kong might be expected to have interfirm relationships mirroring their socio-cultural orientation, just as Western firms reflect their cultural patterns as they transact business. Greater understanding of cultural influence in channel relationships is, thus both overdue and important.

The cultural dimension most likely to influence contractual patterns in the supply chain is that of long-term orientation (LTO) - Hofstede's fifth dimension of national culture (Hofstede 1991.) LTO refers to the cultural propensity to adopt a long term view of social (and business) interactions. This orientation has been used by scholars 
to explain social interaction (e.g., Barkema \& Vermeulen 1997; Newman and Nollen 1996; Hofstede 1991). LTO, is the extent to which a society exhibits a pragmatic future-oriented perspective rather than a conventional short-term point of view (Mooij 1997). Interorganizational relationships in LTO cultures, once established, tend to endure over long periods. Parties to these relationships tend to handle current issues with long-term goals rather than short-term gains in mind. In contrast, exchange parties in cultures exhibiting low LTO tend to engage in relationships that are comparatively short-term and, in turn, to expect supply chain relationships to be relatively short-lived. Many industrialized Western countries are relatively low in LTO as measured by Hofstede (1991).

The purpose of this study is to understand the effect of LTO culture on the contractual relationship between supply chain members. LTO culture has been confirmed at international levels (Nakata \& Sivakumar 1996, Chang \& Ding 1995, Yeh \& Lawrence 1995) and has been accepted as important for describing difference among nations (Newman \& Nollen 1996). However, since LTO as a national culture-characteristic is relatively new, no empirical research has been done on the impact of LTO on the contractual relationships in the supply chain. In this study, we examine the effect of LTO culture on the characteristics of contracts in Korea, as an exemplar of a high LTO culture. The investigation of the influence of LTO may be helpful in understanding contractual relationships formed in a country with differing level of time orientation.

\section{THEORETICAL BACKGROUND \& HYPOTHESES}

\section{Long-Term Orientation(LTO)}

Most scholars (Ganasan 1994; Morgan \& Hunt 1994; Lusch \& Brown 1996) treat LTO at the individual firm level, rather than at the level of national culture. For example, Ganasan (1994) defines LTO as the perception of interdependence of outcomes in which both partner's outcomes and joint outcomes are expected to be realized in the future. Short-term accommodation is desirable to achieve the long term result. LTO as used by these channel scholars is affected by antecedents such as trust and dependence between exchange parties (Ganasan 1994) and these in turn affect other relational variables such as cooperation (Morgan \& Hunt 1994) and relational norms (Lusch \& Brown 1996) among exchange parties. However, LTO at the macro level of nation culture is a predisposition related to cultural formation. Social relationships between exchange partners spring from the cultural milieus of the individual partners. If the embedded cultural orientation is a time orientation (either long or short-term), it is logical to assume that such an orientation may be important in shaping interfirm supply chain interactions.

Members of East-Asian cultures such as Korea, Japan, China, Taiwan, and Hong Kong tend to understand social interactions in the context of the long-term. Their personal, social and business relationships are maintained and reinforced through continuous and long-term associations (Yeung \& Tung, 1996). Both current problems and advantages are generally viewed in the context of outcomes expected in the distant future. These countries foster virtues oriented towards future reward (as opposed to short-term gain) and this orientation is expressed as a high score on the LTO index (Hofstede 1991). Discrete transactions are, for the Asian, generally viewed as part of the larger, more important whole of the on-going relationship.

In the West, by contrast, social transactions of all types are more often seen as isolated occurrences. The objective of any transaction is to achieve optimal "give and take" in that particular transaction. An emphasis is placed on immediate gains from the interaction (Yeung \& Tung, 1996). Countries in which citizens evidence these transaction-focused tendencies (such as the USA, the UK, and Canada) score low on the LTO index (Hofstede 1991). Jacobs (1991) argues that this short-term focus hampers US firms in the development of technologies and products necessary to compete on a global basis. R\&D by its very nature is a lengthy and often uncertain process and therefore antithetical to milieus where a high value is assigned to short-term outcomes. This orientation may undermine the long-run viability of American companies. Jacobs recommends that American companies adopt a longer-term perspective to compete successfully with Japan. 


\section{LTO Measures}

Hofstede (1991) suggests that, among several dimensions, perseverance and thrift reflect LTO most adequately. In the inter-organizational relationship context, these two dimensions appear to have particular relevance.

Thrift: Being thrifty means spending money carefully in the present for later enjoyment. It also means postponing present happiness to the future. Therefore, thriftiness for high LTO cultures represents an orientation towards the future (Yeh \& Lawrence 1995). Hofstede (1991) points out that a high score on the value of thrift in Korea shows very long-term orientation in the culture.

Perseverance: Perseverance is a consistent and determined effort to achieve goals (Hofstede 1991). Goals are future positions an exchange party wishes to attain and goals exist only if the desired position differs from the actual state (Cadotte \& Stern 1979). When an exchange party regards its goals as difficult to achieve, persistence is necessary since attainment cannot be imminent. Persistence focuses on the long-term for payoff for present efforts. Thus, perseverance evidences a high level of long-term orientation. Korea shows high scores on the value of perseverance (Hofstede 1991).

\section{Diverse Cultural Tendencies within a Culture}

Culture is learned and interpreted by its members. The behavior of each member is different depending on the level of learning or interpretation of the culture particular to that individual (Keesing 1974). Therefore, depending on individual's level of acculturation, various degrees of cultural tendencies may be observed (Triandis et al 1985). Keesing (1974, p.89) asserted that "each individual has a variant version of the code. Culture in this view is ordered as a system shaped and constrained by the way the human brain acquires, organizes, and processes information." Thus, as the individual accepts and reflects the culture around him/her, so will exchange parties tend to exhibit their culture as they interact with supply chain partners.

Behavior deviating from a cultural norm is possible. For instance, a party in a STO culture might not fully observe the expected short-term perspective on a supply contract, reflecting that the individual has not adopted this aspect of his/her ambient culture. Thus, Goodenough (1971) suggested that the analysis of cultural influence on behavior must be in individual level, since people learn culture as individuals.

\section{Contracts}

Contracts refer to the promise between exchange parties to project exchange into the future (Macneil 1980). Therefore, contracts shape or attempt to shape relationships in the future and they would not exist unless some expectation of future dealings existed. Since exchange parties cannot predict the future perfectly, the content of contract may not reflect the future contingencies well. Thus, contracts may make the parties vulnerable. Either party may be vulnerable to the other if one tries to take advantage of unclear or missing contract terms (in other words, engages in opportunistic behavior.)

In their explicit protection against possible opportunistic behavior, scholars have divided contracts into two categories: soft contracts and hard contracts. A soft contract refers to the existence of implicit, mutual understandings of expected roles and behaviors on the part of the exchange parties (Smith, Carroll, \& Ashford 1995). The soft contract does not set out specific stipulations since it relies on unstated understandings. Some think of them as incomplete contracts, since large parts of them are unwritten and exist mainly in the understanding of the agreeing parties. Incomplete contracts allow exchange parties to save costs such as costs of searching for information on future contingencies or the costs of writing fully contingent contracts (Klein 2002). However, incomplete contracts may leave the parties vulnerable to opportunistic behavior, since it would be possible to exploit unstated or vague contractual terms.

Soft contracts are useful when the performance of exchange parties is difficult to measure. For instance, a supplier's responsiveness to a customer's urgent request for extra parts cannot be measured easily. There are several 
contingencies involved in the responsiveness to urgent requests such as extent of parts stocks, delivery time allowed the supplier, the price of the parts, etc. Thus, it is not feasible or usually possible for exchange parties to specify all contingencies with regard to measuring the performance of the supplier.

Supply chain members whose relationship has a long-term orientation may accept short-term disadvantages since these may be expected to be balanced out by longer-term advantages (Noordewier, John, and Nevin 1990). Thus, as exchange parties in LTO cultures adopt more and more of their national cultures, they are less likely to engage in short-term self-interested behavior. Instead, they are more likely to perceive and value future benefits, so they seek to continue the relationship with their partners. Through the continued relationship, exchange parties have a better chance of developing mutual understanding. Supply chain partners with long-term perspectives tend to build up implicit guidelines for behavior through soft contracts.

H1: In a high LTO culture, the more an exchange party adopts the national culture, the more the party relies on soft contracts.

Hard contract refers to detailed contractual agreements that specify at length the roles and obligations of the parties (Cannon, Achrol, and Gundlach 2000; Smith, Carroll, \& Ashford 1995). Thus, detailed contractual obligations, or specific rules and regulations would characterize hard contracts. For example, a hard contract between exchange parties generally spells out in detail the penalties for failure to perform designated tasks. Therefore, exchange parties with hard contracts are constrained to behave in the manner required by a written contract.

Hard contracts may be ineffective in prohibiting exchange parties from seeking self-interest for short-term benefits (Cannon, Achrol, and Gundlach 2000; Williamson 1991) because the specific rules and regulations of hard contracts cannot cover all possible contingencies. An opportunistic party can take advantage of ambiguous language or unforeseen circumstances to increase the party's own gain from the contract. Worse still, contract language that adequately reflects the current situation may apply less and less precisely as the years pass. The passage of time thus exposes the parties to even more risks of opportunistic behavior.

In LTO cultures, exchange parties with long-term perspectives expect their relationships to continue over a long period. They expect to harvest the benefits on a longer-term base. Once a relationship ceases, parties lose any chance to profit from it. As dishonesty and opportunistic behavior can terminate relationships, they are avoided--not for contractual reasons but for the sake of continuity. It is continuity, after all, that is regarded as the source of the mutual long-term pay-off. For the high LTO partner, a hard contract cannot guarantee longer-term future benefit. Reliance on the mutual commitment to continuity implicit in the soft contract appears more certain to one who is acculturated in LTO values.

It is of course possible for an exchange party with LTO to write a hard contract. Given, however, the fact that hard contracts are particularly weak in covering future contingencies and the focus on future outcomes in LTO cultures, a hard contract appears unlikely. Therefore, the more exchange parties show long-term orientation tendencies, the less exchange parties would be expected to rely on hard contracts.

H2: In a high LTO culture, there is no relationship between the level of a party's adoption of the national culture and the party's reliance on hard contracts.

\section{RESEARCH DESIGN}

\section{Context}

To test the hypotheses, supply chain relationships between manufacturers and their suppliers in Korea were studied. Korea was selected for two reasons. First, Korea represents a high LTO culture. Hofstede (1991) ranked Korea among the highest cultures on his LTO scale. Second, even though the Korean economy has been developing rapidly over the past 30 years, research on supply chain relationships in Korea is rare. Therefore, this study extends the understanding of supply chain relationships to Korean firms. 


\section{Sample}

Manufacturers in Korea were selected as a systematic random sample of 465 firms from a mailing list of the Korean Manufacturers Association. The manufacturers in this study were drawn from a variety of industries (principally from electronics, metal, textile, and steel industries) to enhance the generalizability of the results by minimizing the effect of industryspecific characteristics. As this research concerns manufacturers' contractual relationships, the heads of purchasing departments of the manufacturing companies were chosen as key informants. Purchasing managers are responsible for securing materials from suppliers, hence they can be expected to be knowledgeable about production input sourcing and the attendant appropriate supplier relationships (Hutt and Speh 1992).

Each informant was mailed a questionnaire and asked to complete it with respect to a major supplier. After callbacks and a second mailing, 101 surveys were collected, yielding response rates of approximately $22 \%$.

The usable responses were tested for nonresponse bias by comparing early respondents with late respondents (Armstrong and Overton 1977). The mean value for each scale (i.e., long-term orientation, soft contract, and hard contract), and the characteristics of the participating companies and the key informants (i.e., years of relationship with the supplier, years of experiences of the respondents as purchasing managers) were compared across the two groups. The comparison results indicated no sign of significant differences between two groups (the $\mathrm{p}$-values for the comparisons ranged from .22 to .31 for Korea data.) In addition, the responding firms were compared with the nonresponding firms based on such characteristics as the numbers of employees and total sales, using the secondary data obtained from Korean Commercial and Manufacturing Association. The comparison results produced no significant differences. Finally the response rates across the different industries in the sample (i.e., electronics, metal, textile, and steel) revealed no significant difference, suggesting that the data are not skewed by non-response bias.

In the pretest, the respondents were evaluated on their qualifications to respond to the survey questions (e.g., Kumar, Stern, and Achrol 1992) based on these criteria: length of time the firm had dealt with their main supplier, duration of tenure in the manager's present job and perceived level of knowledge concerning their contractual relationship with their main supplier. The pre-test results indicated that the respondent companies had an average 13year relationship with their major suppliers and that the respondents had occupied their current positions for 6.4 years on average. The descriptive statistics also suggested that the target sample (i.e., purchasing managers) is qualified to answer the survey with sufficient experience with the main supplier and its product.

\section{Measurement Scale Development}

The Korean version of questionnaire was translated by the first author whose native tongue is Korean. To make sure that the translated questionnaire was identical in Korean and English, a bi-lingual Korean-English colleague back-translated the questionnaire from Korean to English. Several translation differences between two translators were identified and resolved after a discussion between two translators.

Measure scale development was carried out in two stages. First, the existing measures of the focal variables were collected from the literature. Then, in-depth interviews were conducted with three purchasing managers to check the relevance of the collected measures. Wording of some of the items was revised based on the input from the purchasing managers. All items were 7-point Likert-type scales anchored by 1 (strongly disagree) and 7 (strongly agree) as endpoints.

\section{LTO culture}

This scale captures exchange parties' perception of their countries' level of long-term orientation. These responses measure the extent to which exchange parties in the same country had different degrees of personal integration of the LTO perspective. Based on Hofstede's (1991) original wording, each item was adapted by the first author for use in the present context. The three key components of continuity, thrift and perseverance were captured by seven items. These seven items asked respondents the importance of working toward future goals instead of enjoying present pleasures, of working hard today for a better quality of life in the future, of saving money rather than 
spending it today, of being frugal, of making connection with other people, and of postponing one's enjoyment of life to the future.

With reference to a possible cross-cultural effect on the exchange parties' behavior, it is usually pointed out that there are individual differences in the degree of cultural influence on the behavior of group members (Chen, Chen, \& Meindl 1998; Markus and Kitayama, 1991). Any one member of a high LTO culture might respond to items in a manner contrary to the typical member of the culture, reflecting perhaps lower levels of acculturation into the larger cultural pattern. Thus, an exchange party in a high LTO culture could show lower LTO than expected. In this study, the different level of cultural influence on the exchange parties' behavior is considered. Exchange parties are asked their perceptions of the LTO culture of their home country.

\section{Contracts}

Contract type was measured so that hard and soft contracts could be distinguished. Hard contracts were characterized by explicit, precise descriptions of each party's role, responsibilities, legal remedies for performance failures and the method of conflict resolution. Soft contracts were characterized more by the reliance on mutual understanding (as opposed to contract stipulations) of each party's role, responsibilities, remedies for performance failures and the way of resolution for conflict. These items were used by Lusch \& Brown (1996).

\section{Construct Validity}

Each latent variable - Long-Term Orientation (LTO), Soft Contract (SCONT), Hard Contract (HCONT), Buyer Dependence (BUYDEP), and Supplier Dependence (SUPDEP) - that was measured with multiple items was subjected to the scale purification procedure. On the basis of item-to-total correlations, the ill-fitted items were dropped. Among the six items used for LTO, the relative importance of the quality of the future (LTO5) and the postponing of current enjoyment to the future (LTO6) were deleted since these items lowered internal consistency. The subsequent reduced sets of items were subjected to confirmatory factor analysis (CFA) using LISREL. Based on the CFA results, some of the items with low factor loadings were removed from the scales. Finally, coefficient alpha for each construct was measured for reliability test.

After the scale purification process, a measurement model with acceptable fit indices was identified $\left(\square^{2}(32)\right.$ $=41.48(\mathrm{p}=.13), \mathrm{GFI}=.93 \mathrm{AGFI}=0.87, \mathrm{CFI}=.95, \mathrm{RMSEA}=.054)$. All the factor loadings were highly significant $(\mathrm{p}<.01$ ), showing the evidence of convergent validity and unidimsionality of the measures (Anderson and Gerbing 1988).

Discriminant validity of all the 3 latent variables was checked through $\chi^{2}$ Difference Tests: all the constructs in pairs ( 3 tests altogether) were tested if the restricted model (in which the correlation was fixed as one) was significantly worse than the freely estimated model (in which the correlated was estimated freely). All the $\chi^{2}$ differences were highly significant, presenting the evidence of discriminant validity (Anderson and Gerbing 1988). For example, the comparison of soft contract with hard contract yielded a $\square^{2}(1)=25.52(\mathrm{p}<.01)$ for data, suggesting these two constructs are distinct.

Finally, the reliability coefficient of each construct was measured (between 0.71 and 0.82 ). Each factor shows satisfactory level of reliability these results show that the measures in this study possess adequate reliability and validity. The factor loadings, reliability measures of each construct, and as goodness-of-fit index are reported in Table 1. 
Table 1

Measurement Items and Validity

Korea: $\square^{2}(32)=41.48(\mathrm{p}=13), \mathrm{GFI}=.93 \mathrm{AGFI}=0.87, \mathrm{CFI}=95, \mathrm{RMSEA}=.054$

Long-Term Orientation Culture

CR: .71

SFL

Korea

LTO1: working toward future goal

.58

LTO2: working for future life

.81

LTO3: saving money for future

.45

LTO4: being frugal

LTO5: the relative importance of the quality of the future

LTO6: the postponing of current enjoyment to the future

Soft Contract (SCONT) CR: .82

SCONT1: mutual understanding of the roles and responsibility $\quad .53$

SCONT2: mutual understanding of the behavior in case of unplanned event $\quad .80$

SCONT3: mutual understanding of how disagreements will be resolved $\quad .50$

Hard Contract (HCONT) CR: .79

HCONT1: precise definition of roles and responsibility in contract $\quad .73$

HCONT2: detailed direction in contract about behavior for unplanned event $\quad .81$

HCONT3: precise contract statement of how disagreements will be resolved $\quad .71$

Note: * Items deleted from further analysis due to low factor loadings or high cross-loadings. SFL = Standardized Factor

Loading, CR = Composite Reliability.

\section{Control Variables}

We include firm size, relationship length, and power-asymmetry between a manufacturer and its supplier as control variables. Firm size was indicated by the logarithm of the number of employees. Relationship length was assessed by the number of years that the manufacturer has been doing business with the supplier. Power-asymmetry was calculated by the deduction of supplier's dependence from its buyer's dependence.

Table 2

Means, Standard Deviations, and Correlations for Constructs

\begin{tabular}{|lcccccc|}
\hline & 1 & 2 & 3 & 4 & 5 & 6 \\
\hline 1. LTO (LTO) & 1.00 & & & & & \\
2. Soft Contract (SCONT) & .21 & 1.00 & & & & \\
3. Hard Contract (HCONT) & .00 & .26 & 1.00 & & & \\
4. Power Asymmetry (POWASYM) & -.07 & -.02 & .05 & 1.00 & & \\
5. Company Size (SIZE) & -.14 & -.04 & -.02 & -.16 & 1.00 & \\
6. Relationship Length (LENGTH) & .07 & .16 & -.03 & -.08 & .00 & 1.00 \\
Mean & 5.41 & 5.22 & 4.68 & 0.21 & 4.36 & 13.13 \\
Standard Deviation & .72 & .71 & 1.35 & 1.00 & 1.56 & 9.34 \\
\hline
\end{tabular}

\section{ANALYSIS AND RESULTS}

\section{Tests of Hypotheses}

The hypotheses were tested formally with multiple regressions. Four tests were done to verify the hypotheses. The first test was for hypotheses 1 . The dependent variable in the regression model was soft contract (SOFTC). The independent variables included time-orientation of the culture (LTO) and power asymmetry (POWASYM). Power asymmetry between exchange parties was added, since the interfirm power relationship might be a factor which 
influence the adoption of specific contract. The equation was structured as follows:

SOFTC $=b 0+b 1$ LTO $+b 2$ POWASYM $++b 3$ FIRMSIZE $+b 4$ LENGTH $+u i$

Where

$b 1, b 2, b 3, b 4=$ coefficient

$u i=$ an error term

The second test was done with hard contract (HARDC) for hypothesis 2. The same independent variables used in the first test were included. The results are shown in Table 3.

Table 3

Regression Analysis for Hypotheses

\begin{tabular}{lcc}
\hline & \multicolumn{2}{c}{ Dependent Variables } \\
Independent Variables & SCONT & HCONT \\
LTO & .212 & .004 \\
SIZE & $(2.140)^{\mathrm{a}}$ & $(.045)$ \\
LENGTH & -.018 & -.010 \\
POWASYM & -.172 & $(-.090)$ \\
Adj. $\mathrm{R}^{2}$ & .147 & -.026 \\
& $(1.482)$ & $(-.254)$ \\
\end{tabular}

$\mathbf{a}:$ reject Ho at $\mathrm{p}<.05$ (1-tailed test.)

The results in Table 3 show that LTO culture in Korea is positively associated with soft contracts $(\beta=.212$, $p$ $\leq .05$ ). This suggested that as exchange parties in Korea adopt the prevalent national culture (LTO), they are likely to rely on soft contracts. This result supports H1.

Similarly, results show that exchange parties in LTO culture do not rely on hard contracts, which supports H2. Exchange parties with high long-term orientation culture in Korea do not tend to depend on hard contracts.

\section{Summary of Hypotheses Tests}

Hypothesis testing supports the claim that, as supply chain members adopt LTO characteristics, they will tend to favor soft contracts with suppliers. Further, the data suggest that there is no basis for supposing that Korean supply chain members will rely on hard contracts. The usual expectation and practice in Korea is the soft contract, and this expectation is elevated as supply chain members evidence higher levels of LTO acculturation.

It is interesting to note that, in terms of contract preference, none of the control factors (firm size, length of relationship between the parties or inter-organizational power asymmetry) predicted contract type well. The power of the LTO cultural variable in influencing contract preference is unassailable.

\section{DISCUSSION}

Most of the newly developing countries in Asia are characterized by inter-organizational relationships peculiar to them (Kale 1986). It is tempting to conclude that the level of economic development is a significant determinant of inter-organizational relationships across cultures globally, such that these relationships everywhere might be understood by determining the economic status of the country of interest. This research shows that such a 
conclusion is unwarranted. Instead, the influence of cultural values is of significant importance and may not be disregarded when considering these relationships. Cultural factors may be of greater importance, in fact, given the elimination of variables like firm size or power asymmetry as important predictors of contract type selection.

This study shows that firms in a high LTO culture tend to prefer and use soft contracts in the relationship between supply chain members. When Korean firms expect their relationships with partners to continue into the future, they are likely to develop mutual understanding of expected roles and behaviors. Since future contingencies are difficult to predict, exchange parties develop mutually acceptable behavior standards to deal with future contingencies. It is difficult for exchange parties to deal with uncertain future contingencies with hard contract that specify specific behavior (Ford et al 1998). Thus, exchange parties in Korea are more likely to develop soft contracts that facilitate future benefits by permitting adjustments as contingencies arise based on implicit assumptions of mutual gain.

\section{Managerial Implications}

Western firms with supply chain partners in Asia should be aware that the nature of contract they propose is not "culture-neutral." Soft contracts in LTO countries were evolved from cultural assumptions quite different from the motives guiding contract choices on home soil. When US companies establish manufacturing facilities in EastAsia, they should both expect and seek to resolve time-orientation issues. If they want short-term benefits in the relationship with local customers or suppliers, they may encounter difficulties due to the mismatch of time orientation. Asian firms might feel uncomfortable with US companies that insist on explicit contracts. An explicit contract may be simply "good business" to an American business person while the exchange partner might regard it as proof of unwillingness to establish a long-term relationship. This misunderstanding might jeopardize possible fruitful relationships with LTO partners.

\section{Limitations \& Future Research}

We examined only one dimension of culture, that is, long-term orientation. The study does not include other cultural dimensions such as collectivism, or power distance, risk avoidance, and masculinity (Hofstede 1991). Among the cultural dimensions, collectivism/individualism has shown strong empirical results (Triandis, 1995). Thus, collectivist culture may have a strong influence on exchange parties. For instance, if a member of a collectivist culture asserts self-interest too much, it would be viewed as a challenge to the relationship between members (Chen, Chen, \& Meindl 1998), since collectivist culture stresses cooperation between members (Wagner 1995). Thus, exchange parties adopting collectivist culture will be less likely to engage in self-serving behavior. Thus, exchange parties tend not to worry about opportunistic behavior on the part of their partners. Exchange parties in collectivist cultures may be expected to rely on soft contracts, certainly more often that their counterparts in individualist cultures do.

The other end of the time-orientation spectrum must be investigated. If high LTO cultures tend to rely on soft contracts as a function of their LTO acculturation, would low LTO (i.e. more short-term focused) supply chain members be expected to rely on hard contracts in the same way? There is some indication that this is not the case. Macaulay (1963) reports that in most manufacturing situations in Wisconsin, businessmen prefer to rely on "a man's word" in a brief letter and a handshake even when the transaction involves exposure to serious risks. Thus, exploration of the relationship between culture and contract-type needs to be extended carefully since easy analogies may not be accurate.

\section{REFERENCES}

1. Anderson, Erin and Barton Weitz (1989), Determinants of Continuity in Conventional Industrial Channel Dyads, Marketing Science, 8(4): 310-323.

2. Antia, Kersi and Gary Frazier (2001), The Severity of Contract Enforcement in Interfirm Channel Relationship, Journal of Marketing, 65(October): 67-81.

3. Axelrod, R (1984), The Evolution of Cooperation. New York: Basic Books. 
4. Bacharach, Samuel B. and Edward J. Lawler (1981), Bargaining: Power, Tactics, and outcomes, JosseyBass: San Francisco.

5. Barkema, Harry and Freek Vermeulen (1997), What Differences in the Cultural Backgrounds of Partners are Detrimental for International Joint Ventures? Journal of International Business Studies, 28 (4): 845-864

6. Bello, Daniel C. and David I. Gilliland (1997), The Effect of Output Controls, Process Controls, and Flexibility on Export Channel Performance, Journal of Marketing, 61(January): 22-38.

7. Buvik, Arnt, Torger Reve (2001), Asymmetrical Deployment of Specific Assets and Contractual Safeguarding in Industrial Purchasing Relationships, Journal of Business Research, 51(2): 101-113.

8. Cadotte, Ernest and Louis Stern (1979), A Process Model of Interorganizational Relations in Marketing Channels, in Research in Marketing, Vol. 2 Jagdish Sheth, ed., JAI Press: Greenwich, CT

9. Cannon, Joseph, Ravi Achrol, and Gregory Gundlach (2000), Contracts, Norms, and Plural Form Governance, Journal of the Academy of Marketing Science, 28(2): 180-194

10. Cartwright, Bliss C., and Schwartz, Richard D.(1973). The invocation of legal norms: an empirical investigation of Durkheim and Weber, American Sociological Review, 38: 340-354.

11. Chang, Juochung and Cherng G. Ding (1995), The Influence of Culture on Industrial Buying Selection Criteria in Taiwan and Mainland China, Industrial Marketing Management, 24: 277-284.

12. Chiles, Todd H. and John F. Mcmackin (1996), Integrating Variable Risk Preferences, Trust, and Transaction Cost Economics, Academy of Management Review, 21(1): 73-99.

13. Doney, Patricia M. and Joseph P. Cannon (1997), An Examination of the Nature of Trust in Buyer-Seller Relationships, Journal of Marketing, 61(April): 35-51.

14. Dore, R (1987), Taking Japan seriously, Stanford University Press: Stanford, CA

15. Dwyer F. Robert, Paul H. Schurr, and Sejo Oh (1987), Developing Buyer-Seller Relationships Journal of Marketing, 51(April): 11-27.

16. Etger, Michael and Aharon Valency (1983), Determinants of the Use of Contracts in Conventional Marketing Channels, Journal of Retailing, 59(Winter): 81-92.

17. Foa, Uriel and Enna Foa (1974), Societal Structures of the Mind, Charles C. Thomas: Springfield, IL

18. Ford, David, Lars Gadde, Hakan Hakansson, Anders Lundgren, Ivan Shehota, Peter Turnbull, and David Wilson (1998), Relationships and Technology, in David Ford (Ed.), Managing Business Relationships, Wiley \& Sons Ltd: England.

19. Frazier, Gary L (1983) Interorganizational Exchange Behavior in Marketing Channels: A Broadened Perspective, Journal of Marketing, 47(Fall): 68-78.

20. Ganesan, Shankar (1994) Determinants of Long-Term Orientation in Buyer-Seller Relationships, Journal of Marketing, 58(April): 1-19.

21. Gudykunst, William B.(1988) Culture and Intergroup Processes, in M. Bond (Ed.), The Cross-Cultural Challenge to Social Psychology, Sage Publication: California.

22. Gundlach, T. Gregory and Ernest R. Cadotte (1993), Exchange Interdependence and Interfirm Interaction: Research in a Simulated Channel Setting, Journal of Marketing Research, 31(November): 516-532

23. Heide, Jan B. and George John (1992), Do Norms Matter in Marketing Relationships? Journal of Marketing, 56(April): 32-44.

24. Hill, Charles W. (1990) Cooperation, Opportunism, and the Invisible Hand: Implications for Transaction Cost Theory Academy of Management Review, 15(3): 500-513.

25. Hofstede, Geert (1991), Cultures and Organization: Software of the mind, McGraw-Hill London.

26. Jacobs, Lawrence (1991), Short-Term America, Sage Publication: London.

27. Kale, Sudhir H. (1986) Dealer Perceptions of Manufacturer Power and Influence Strategy in a Developing Country, Journal of Marketing Research, 23(November): 387-393.

28. Keesing, Roger (1974), Theories of Culture, Annual Review of Anthropology, 3, 73-97.

29. Klein, Benjamin (2002), The Role of Incomplete Contracts in Self-enforcing Relationship, in Eric Brousseau and Jean-Micael Glachant (Ed.) The Economics of Contracts, Cambridge University Press, England.

30. Kumar, Nirmalya, Lisa K. Scheer, and Jan-Benedict E. M. Steenkamp (1995), The Effect of Perceived Interdependence on Dealer Attitudes, Journal of Marketing Research, 32(August): 348- 356.

31. Lawler, Edward J. and Samuel B. Bacharach (1987), Comparison of Dependence and Punitive Forms of Power, Social forces, 66(2): 446-462.

32. Lusch, Robert F. and James R. Brown (1996), Interdependency, Contracting, and Relational Behavior in 
Marketing Channels, Journal of Marketing, 60(October): 19-38.

33. Mackneil, Ian R. (1980), The New social Contract, Yale University: New Haven, CT.

34. Moorman, Christine, Gerald Zaltman, and Rohit Deshpande (1992), Relationship Between Providers and Users of Market Research: The Dynamics of Trust Within and Between Organizations, Journal of Marketing Research, 29(August): 314-328.

35. Mooij, Marieke De. (1997), Global Marketing and Advertising: Understanding Cultural paradox, Sage Publication: London.

36. Morgan, Robert M and Shelby D. Hunt (1994), The Commitment-Trust Theory of Relationship Marketing, Journal of Marketing, 58(July): 20-38.

37. Nakata, Cheryl and K. Sivakumar (1996), National Culture and New Product Development: An Integrative Review, Journal of Marketing, 60(January): 61- 72.

38. Newman, Karen L. and Stanley D. Nollen (1996), Culture and Congruence: The Fit between Management Practices and National Culture, Journal of International Business Studies, 27(4): 753-779.

39. Noordewier, Thomas G., George john, and John R. Nevin (1990), Performance Outcomes of Purchasing Arrangements in Industrial Buyer-Vendor Relationships, Journal of Marketing, 54(October): 108-122.

40. Ouchi, W. G. (1981), Theory Z, Avon: New York

41. Provan Keith G. and Steven J. Skinner (1989), Interorganizational Dependence and Control as Predictors of Opportunism in Dealer-Supplier Relations, Academy of management Journal, 32(1): 202-212.

42. $\quad$ Rokeach, Milton (1973), The Nature of Human Values, The Free Press: New York.

43. Sheth, Jagdish N., David M. Gardner and Dennis E. Garrett (1988), Marketing Theory: Evolution and Evaluation, John Wiley \& Sons: New York.

44. Smith, Ken, G., Stephen J. Carroll, and Susan J. Ashford (1995), Intra- and Interorganizational Cooperation: Toward a Research Agenda, Academy of Management Journal 38(1): 7-23.

45. Williamson, Oliver (1975), Markets and hierarchies, The Free Press: New York.

46. Williamson, Oliver (1991), Comparative Economic Organization: The Analysis of Discrete Structural Alternatives, Administrative Science Quarterly, 36(June): 269-296.

47. Yeh, Ryh-Song and John J. Lawrence (1995), Individualism and Confucian Dynamism: A Note On Hofstede's Cultural Root To Economic Growth, Journal of International Business Studies, 26(3): 655-669.

48. Yeung, Irene Y. M. And Rosalie L. Tung (1996), Achieving Business Success in Confucian Societies: The Importance of Guanxi (Connection), Organizational Dynamics, 25(2): 54-65. 


\section{NOTES}

